\title{
RELATIVE AND ABSOLUTE MOBILITY RATES IN THE UNITED STATES
}

\author{
L. Keith Miller \\ University of Kansas
}

\begin{abstract}
Data on social mobility presented by Lipset and Bendix were subjected to further mathematical and statistical analysis to eliminate several confounding variables. First, an information theory correlation coefficient was used to eliminate the effect of technological change factors; second, the stable state of the occupational structure was derived using Markov theorems; and third, attenuation of the correlation due to un reliability of measuring occupational status was corrected by statistical means. It was found that the rigidity of American society was very high ( $87 \%$ of the variance in son's status could be predicted from a knowledge of father's status). Some evidence was also adduced to indicate that European rigidity is even greater than that of American society. These results suggest that when we correct for technological shifts in the occupational structure and for attenuation due to unreliability, and when the stable state of that structure is examined, we obtain a picture of a very rigid. society.
\end{abstract}

Lipset and Bendix (1960) have presented rather extensive evidence from which they conclude that the intergenerational mobility rate in the United States is quite comparable with the rates in other industrialized societies. Furthermore, they conclude from their study that the absolute rates are much higher than stratification theorists generally $1 \mathrm{mply}$. These conclusions would seem to suggest that a substantial reshaping of stratification theory may be necessary.

The present paper contains a mathematical reanalysis of a portion of the raw data from which Lipset and Bendix draw their conclusions. Two additional factors are introduced into our understanding of mobility throughout this reanalysis: the effect of a changing industrial structure and the effect of an imperfect measurement of occupational status. Both factors are capable of obscuring the degree of intergenerational mobility within a society. Thus, an industrial structure rapiliy changling 1 ts proportion of white and blue collar workers would temporarily appear to be a highly mobile soclety. Likewise, a soclety in which the true occupational status is not accurately measured would appear more mobile than it actualiy is. The present paper uses mathematical methods for assessing intergenerational mobility rates with these two factors controlled.

\section{Me asurement of Rigidity}

Lipset and Bendix have measured the soclal mobility of both European and American societies. They express this as the percent of the population who have moved into a non-manual occupation when their father occupied a manual occupation, or the converse.

The measure used by Lipset and Bendix provides us with an index of the amount of mobility in a society, but says nothing about the sources of that mobility. Kahl (1953. chap.IX) has singled out four such sources: Individual, immigrant, reproductive, and technologlcal mobility. According to his estimate, lmmigrant and reproductive mobllity accounts for very little of the United States' pattern. He finds that individual and technologlcal sources of mobility account for most 
of the pattem, with individual mobility about twice as important as technological mobility (1953: 259-262).

If these estimates are even approximately correct, they suggest that the inheritance of jobs between generations may be obscured in times of great technological change; that is, a country may appear to have little inheritance even though the actual normative structure allows little else than inheritance. Thus whether one is comparing the same country at different times or different countries at the same time, the absolute mobility rates may not reveal the actual normative structures.

Even before Kahl's approximations confirmed the need for it, various methods had been developed to "factor out" the contribution of technological change. All of these methods were based on the notion that the ability to predict a son's category from a knowledge of the father's is direct evidence of inheritance, regardless of whether some sons "move" from their father's category. For example, if all sons were to move exactly two "units" upward from their father's position, the perfect predictability would constitute evidence for complete rigidity. One method used to measure this predictability has involved computing a correlation coefficient (Rogoff 1953:23). Another method relies on an index deriving from Chi-square (Rogoff 1953 and Glass 1954).

Both of these measures eliminate the effect of technological change by directly measuring the effect of father's category on son's regardless of the general nature of the distribution of jobs. Unfortunately neither of them relies upon a sound measure of association, partly because such a measure had not been devised for contingency tables. Recently, however, a method based on information theory has been developed which is completely comparable to the Pearson coefficient of determination $\left(r^{2}\right)$ when utilized in contingency tables. ${ }^{2}$ The present analysis utilizes this measure.

"Rigidity" of the structure is measured by correlating father's occupational status with son's occupational status. If the index is 1.00 then father's status completely determines son's status and total rigidity is indicated. If the index is 0.00 then son's status is completely independent of father's status and total mobility is indicated. This index controls for industrial changes by measuring predictability of son's status given father's status. This predictability can be high even if the son's status is different from father's status. Thus, if there is a general upward trend in the status structure, this index will measure the extent to which it is predictable from father's status who will move up and how far they will move. Thus, this index measures only individual mobility while eliminating the effect of technological change on the overall index of mobility.

\section{United States and Europe Compared}

Table I records every European country appearing in the Lipset and Bendix study. In the column headed "\% non-mobile" the table records an index of occupational rigidity. The column shows that $69 \%$ of all non-farm Americans are non-mobile as compared with $72 \%$ of Europeans. The ratio between these two indices is 1.05 , probably an indication of no substantial difference.

The other two columns in the table record the correlation indices just described with and without farmers included in the analysis. Thus, with farmers excluded from the analysis, $9 \%$ of the variation in son's status can be predicted with a knowledge of father's status. The average figure for European countries is 
about $13 \%$, or one-half times greater. This means that a knowledge of father's status will allow $50 \%$ greater predictabllity of son's status in Europe. The same pattern of comparison seems to hold when each European country is examined individually; they all show a degree of rigidity which is higher than that in the United States. Thus it is clear that European rigidity is substantially greater than that in the United States when the effect of technological change is held constant.

While Bendix and Lipset undertook their analysis with farmers excluded (partly because of their index), the last two columns show the results with farmers included. U.S. rigidity is somewhat higher when farmers are taken into account; European rigidity seems to be correspondingly higher; however, the same ratio obtains whether farmers are included or excluded.

Table 1. The Rigidity of U.S. Compared with European Societies

\begin{tabular}{lccc}
\hline & & \multicolumn{2}{c}{ Correlational Data } \\
Country & $\begin{array}{c}\text { Non-Mobile and } \\
\text { Farmers }\end{array}$ & $\begin{array}{l}\text { Farmers } \\
\text { Excluded }\end{array}$ & $\begin{array}{l}\text { Farmers } \\
\text { Included }\end{array}$ \\
\hline United States & 69 & 9.0 & 14.3 \\
Germany & 70 & 11.9 & 19.8 \\
Sweden & 71 & 14.2 & 12.8 \\
France & 73 & 14.3 & 24.6 \\
Switzerland & 77 & 12.8 & 24.5 \\
& 72 & 13.2 & 21.8 \\
Europe & 1.05 & 1.47 & 1.52 \\
Ratio & & & \\
\hline
\end{tabular}

It is possible that the comparison of U.S. and Europe is unduly affected by the present shape of the job distribution, even though the effect of technological change has been factored out. One might examine each society after the effects of present technological changes have stabilized. This may be done by examining the distribution of jobs which will obtain if present trends in the distribution continue until a stable state is reached. This stable state is easily determined by means of simple Markov theorems. 3 
Table 2. The Rigidity of U.S. and Europe with Steady State Distributions

\begin{tabular}{lcc}
\hline Country & $\begin{array}{l}\text { Farmers } \\
\text { Excluded }\end{array}$ & $\begin{array}{l}\text { Farmers } \\
\text { Included }\end{array}$ \\
\hline United States & 9.1 & 8.7 \\
Ge rmany & 11.2 & 17.0 \\
Sweden & 15.3 & 14.7 \\
France & 14.2 & 24.7 \\
Switzerland & 4.8 & 15.3 \\
Europe & 12.4 & 20.1 \\
Ratio & 1.36 & 2.31 \\
\hline
\end{tabular}

The stable state with farmers excluded indicates very little change in the comparison between U.S. and European rigidity ( $9 \%$ versus $12.4 \%$ ) although the difference becomes somewhat less. However, since some societies are undergoing intensive technological changes in farming, this exclusion grossly distorts the final state. With farmers included, we find that the stable state will result in less than half as much predictability in the U.S. when compared with Europe. If this stable state with farmers included is taken as the best picture of the normatively based rigidity in a society, then it becomes apparent that there are substantial differences between the U.S. and Europe.

The present analysis goes beyond Lipset and Bendix's original analysis by examining rigidity with the effect of technological changes eliminated. The results suggest that the normative structures do in fact differ, although present crude rates may be quite comparable.

\section{Absolute Rigidity in the United States}

A major difficulty which is encountered in studying intergenerational occupational mobility arises from the lack of specificity as to what it is that is being inherited. Is the last occupation held by father inherited; or is it the occupation of the father during the youth or adolescence of the son? The same problem arises from the perspective of the son: do we examine the son's first job or the job he had held longest, or his job at the time he is interviewed?

Most previous studies have gathered the data which are most accessible. These data usually deal with either the major job of the parent or the last one he held, and this is cross-tabulated with the present position of the son. Yet we know that a substantial amount of intra-generational mobility exists; the son's current job may not be the most "representative" of his career. To the extent that this is true, the apparent relationship between father's and son's occupation will be statistically attenuated, that is, decreased in size.

The amount of the attenuation between two variables is controlled by the reliability with which the variables are measured. If the same measurement on the same object is repeated at two different times, the measurement is reliable to the 
extent that the results are the same. This may be expressed as the correlation between the two measurements. In the present case the reliability of a person's job as an indicator of his career may be measured by correlating his job catagory at two different points in time.

If the errors (unreliability) in the measurement of a person's career are not systematic then the true correlation between father and son's career is given by

$$
\mathrm{Rig}_{\mathrm{T}}=\mathrm{Rig}_{0} / \mathrm{R}_{\mathrm{f}} \mathrm{R}_{\mathrm{S}}
$$

where $\mathrm{Rig}_{\mathrm{T}}$ stands for the rigidity index of a society (correlation between father and son), the subscript $T$ meaning the true value of that index while the subscript 0 means the observed value; $\sqrt{R_{f}}$ and $\sqrt{R_{s}}$ stand for the reliability with which the career of father and son is measured (See Walker 1953:300).

Lipset and Bendix present data on the intergenerational rigidity in California (Walker 1953:168). With farmers excluded, the reliability is .258. If the reliability is similar for both father and son (a somewhat dubious assumption necessitated by the lack of data) we then find: $\mathrm{Rig}_{\mathrm{T}}=.090 / .258=.336$. This means that, where we are able to accurately measure the true status of father and son in the United States, about one-third of the variation in son's status would be predictable from a knowledge of the father's status. This is evidence of rather substantial predictability. (The correlation coefficient $r$ is of course slightly less than .60.)

With farmers included, the reliability is .164 . This leads to the estimate $\mathrm{Rig}_{\mathrm{T}}=.143 / .164=.873$. Thus with farmers included we must conclude that the inheritance of occupational status in the United States from one generation to the next is almost perfect.

\section{Dis cussion}

Most analyses of occupational mobility are limited by less than perfect data. This paper has suggested three problems from which much mobility data suffer: confounding of different sources of mobility; restriction to the present in a constantly changing structure; and the unreliable measurement of status. Mathematical and statistical methods for partially overcoming these limitations were described and their use illustrated on data originally published by Lipset and Bendix in which American and European mobility were compared.

First, the use of a correlation coefficient was suggested to eliminate the confounding of technological and individual sources of mobility. This permits the analysis of individual mobility in a society undergoing general upward or downward changes of status. By focusing on the predictability of son's status from father's status, the general changes are factored out. The use of such a measure indicated that European society is as much as $50 \%$ more rigid than American society in spite of almost equal total rates of mobility.

Second, projection of the stable state of the structure through Markov theorems permits an estimate of the future structure from a knowledge of the present structure. The use of such an estimate indicated that European society is more than twice as rigid as American society.

Third, it was suggested that correlational analysis be used to correct for attenuation due to unreliable measurements. This unreliability is reflected in frequent changes in jobs and job status by many persons in the work force. It is well-known to statisticians that such unreliability will generally lower the pre- 
dictability of one measure by another measure--in the present case causing us to underestimate the rigidity of a society. By using a correction for attenuation, the present analysis found that the predictability in American society--the occupational rigidity--is almost $90 \%$ of the variance. This suggests that the true normative rigidity in American society is considerably higher than the crude data would have suggested. A further pursuit of the comparison between American and European structures must await data that will permit correction of the European rigidity index for attenuation. If that correction produces a similar result, then it will provide evidence that Western society is quite rigid indeed.

\section{Footnotes}

${ }^{1}$ Approximately one third of the population is mobile.

2 W. J. McGill,"Isomorphism in Statistical Analysis" in H. Quastler Information Theory in Psychology. Glencoe, Illinois: Free Press. If this measure is applied to a normally distributed equal interval bivariate distribution, the result will be identical with the correlation coefficient. The coefficient lies between the ranges of 0 and 1 .

${ }^{3}$ See John G. Kemeny and J. Laurie Snell, Finite Markov Chains. New York: D. Van Nostrand Co. Inc. 1960. See pp. 191-200. The basic idea is that if $20 \%$ of the sons of white collar fathers become blue collar while $40 \%$ of sons of blue collar become white collar, then ultimately two thirds (67\%) of the population will be white collar. This is referred to as the stable rate.

\section{References}

Glass, D. V. 1954 Social Mobility in Britain. London: Routledge \& Kegan Paul, Ltd.

Kah1, Joseph 1953 The American Class Structure. New York: Rinehart \& Company.

Kemeny, John G. and Laurie Snell 1960 Finite Markov Chains. New York: D. Van Nostrand Company, Inc.

Lipset, Seymore Martin and Reinhard Bendix 1960 Social Mobility in Industrial Society. Berkeley, California: University of California Press.

McGill, W. J. 1960 "Isomorphism in Statistical Analysis." In H. Quastler (ed.), Information Theory in Psychology. Glencoe, Illinois: Free Press. 
Rogoff, Natalie

1953 Occupational Mobility. Glencoe, Illinois: Free Press.

Walker, Helen

1953 Statistical Reference. New York: Holt, Rinehart and Winston. 